\title{
O ENSINO DA CLASSIFICAÇÃO INTERNACIONAL DE PATENTES (CIP) NOS CURSOS DE BIBLIOTECONOMIA BRASILEIROS
}

\author{
LA ENSEÑANZA DE LA CLASIFICACIÓN INTERNACIONAL DE \\ PATENTES NOS CURSOS DE BIBLIOTECOLOGIA DO BRASIL
}

\author{
Joana Coeli Ribeiro Garcia - joanacoeli@uol.com.br \\ Doutora em Ciência da Informação pela Universidade Federal do Rio de Janeiro/ Instituto \\ Brasileiro de Informação em Ciência e Tecnologia (UFRJ/IBICT). \\ Professora do Departamento de Ciência da Informação da Universidade Federal da Paraíba \\ (UFPB).

\section{Francisca Justino Franklin Chacon} \\ Bacharel em Biblioteconomia pela Universidade Federal da Paraíba
}

\section{Resumo}

Ao identificar em quais Cursos de Biblioteconomia a Classificação Internacional de Patentes (CIP) é ensinada, pretende-se despertar nos profissionais da área a necessidade de conhecer ou de aprofundar tais conhecimentos. Os cursos, objeto do estudo, foram identificados por meio do site da Associação Brasileira de Educação em Ciência da Informação (ABECIN). A técnica utilizada é o survey, tendo o e-mail como instrumento de envio do questionário e recebimento das respostas que formam a amostra da pesquisa. $\mathrm{O}$ instrumento de pesquisa foi o questionário, formulado com perguntas abertas. Embora o documento de patente contenha informações relevantes para promoção do desenvolvimento tecnológico das nações, ainda não recebe um tratamento condizente das instituições brasileiras de ensino, ou seja, na maioria dos cursos em que se estudam formas de classificar o conhecimento, a CIP sequer é citada nas disciplinas.

\author{
Palavras-chave \\ Classificação Internacional de Patentes. Ensino \\ da Classificação Internacional de Patentes. \\ Classificação de Patente.
}




\section{PALAVRAS INICIAIS}

No processo de transformação da sociedade, os diversos campos do conhecimento, com destaque para o sóciocultural, o econômico, o científico e o tecnológico estão em constante desenvolvimento. Para que isso seja possível, importantes fatores alavancam a evolução dos modos de produção da sociedade. Exemplo disso é a revolução industrial, cuja criação e uso intensivo das máquinas proporcionam a produção em série, em substituição à manufatura exercida pelo homem, e responsabilizada por mudanças com reflexos até os dias atuais.

Em uma dessas transformações, surge a sociedade do conhecimento, que teve seu primeiro impulso com a criação da imprensa, cuja contribuição fez a comunicação fluir com mais rapidez, para um número maior de interessados. Paralelamente ao surgimento da sociedade do conhecimento, as tecnologias de informação e comunicação favorecem a quantidade de informação disponível, o que resulta em pesquisas e descobertas científicas e tecnológicas que geram novas informações, possibilitando às pessoas novas formas de transmissão da informação e comunicação e novas riquezas para o bem-estar do homem.
Esse processo - informação $\rightarrow$ conhecimento $\rightarrow$ nova informação - reforça a necessidade de organização, utilizandose formas e técnicas corretas de representar esses conhecimentos por meio de sistemas adequados, incluindo-os nos estoques das bases de dados, das bibliotecas, dos arquivos, dos centros de pesquisas, etc. Essa organização objetiva a que, no momento da busca, tal informação seja recuperada, de maneira eficaz e eficiente, e possa, ao ser absorvida, novamente se transformar em conhecimento científico e tecnológico.

No caso da ciência, esse conhecimento tem sido representado por meio de sistemas gerais, sendo os mais conhecidos a Classificação Decimal de Dewey e a Classificação Decimal Universal, respectivamente CDD e CDU. Quanto à tecnologia, supõe-se que também tenha se realizado com base nesses sistemas especialmente criados para representar a ciência. Na realidade, tanto a CDU quanto a CDD são sistemas utilizados indiscriminadamente para classificar informações de todas as áreas do conhecimento, sejam elas científicas ou tecnológicas, dificultando a recuperação da informação tecnológica, visto não ser um sistema para classificá-la com as especificidades requeridas.

Por essa razão, questionamos se as áreas da Biblioteconomia e da Ciência da Informação, como as que têm, até o 
momento, o domínio do conhecimento teórico para gerar tais sistemas, preocupam-se com a classificação da tecnologia. A ausência de obras sobre a prática da classificação das áreas especializadas, dentre elas, a tecnologia, dificulta o trabalho de classificadores $\mathrm{e}$ indexadores que têm que recorrer a artifícios, ou realizar combinações de termos para poder classificar alguns itens, pois determinados assuntos não constam na classificação ou ainda o termo sozinho não representa o assunto ou se encontra inadequado, tendo que se usar semelhança ou aproximação.

Ratificando o problema acima, Veiga e Martha (1986) enumeram alguns problemas da CDU, tais como a análise das facetas feita de forma intuitiva, carecendo de consistência, a manutenção dos assuntos compostos herdados dos sistemas tradicionais, constituindo imprecisão e, por último, a falta de atualização, existente desde 1927, acarretando interpretações erradas e obras mal classificadas.

Essas dificuldades não são problemas atuais dos sistemas de classificação, elas são realçadas, principalmente, quando da necessidade de especificidades. Autores com textos antigos como Kapsner (1956), relata que uma biblioteca especializada utilizava a CDD, mas, devido à inadequação em algumas classes, passou para a Library of Congress (LC), suplementada pelo esquema de Lynn (desenvolvido pela Associação de Bibliotecas Católicas), para solucionar a dificuldade de encaixar alguns assuntos nas classificações existentes.

A superficialidade de cabeçalhos de alguns sistemas de classificação, impedem que classificadores e indexadores aprofundem e ampliem o uso de termos e palavras-chave. Isso se reflete em serviço limitado de entradas, dificultando aos usuários recuperar seus itens de informação de forma adequada e satisfatória.

Veiga e Martha (1986) e Kapsner (1956) indicam que, mesmo com as revisões, os sistemas de classificação podem ser inadequados para classificar e representar estoques especializados, como - que apresentamos nesse estudo a tecnologia representada em documentos de patentes.

Outros autores com textos mais recentes Danuello e Guimarães (2005) discutem em eventos de docentes do Mercosul aspectos relacionados ao ensino da área: tratamento temático da informação (TTI). Eles iniciam apresentando, em um quadro, as recomendações de cada um dos eventos, dentre eles o de Buenos Aires, de 1997, em que é estabelecida uma ementa comum que permita aos docentes comparar temáticas específicas desenvolvidas nos produtos e nos 
conteúdos dos planos de ensino.

Destacam-se os seguintes itens:

Classificação. Indexação. Resumo. Linguagens documentais (sistemas de classificação, listas de cabeçalhos de assunto e tesauros); [...] Planejamento, construção, desenvolvimento, uso e avaliação de linguagens documentais (sistemas de classificação, listas de cabeçalhos de assunto e tesauros). (DANUELLO; GUIMARÃES, 2005, p.157).

A disparidade entre ementas e a possibilidade dos Cursos de Biblioteconomia ministrar os conteúdos referentes ao tratamento temático ou à classificação, por meio de disciplinas com denominações variadas como Indexação Pré-coordenada I e II e Indexação Póscoordenada contribuem para a diversidade inclusive dos assuntos a serem tratados em salas de aula. $\mathrm{Na}$ atualidade com a adoção do novo Projeto Político Pedagógico tal denominação foi reformada em Representação Temática da Informação (na Universidade Federal da Paraíba), na qual além das classificações pré e pós-coordenadas, são também ensinados os conteúdos referentes aos tesauros, às ontologias e às taxonomias. Porém importa conceder relevância ao que ficou estabelecido no Encontro de Santiago, em 1998, ou seja: "capacitar o futuro profissional da informação na organização e no tratamento temático da informação bem como na geração de instrumentos para sua recuperação". (DANUELLO; GUIMARÃES, 2005, p.157).
Garcia (2007), estudando usuários institucionais e individuais de documentos de patentes, formula a hipótese de que a dificuldade para localizar patentes se deve ao desconhecimento da Classificação Internacional de Patentes (CIP), sistema utilizado para organizar, estocar e recuperar tal informação. $E$ mais que isso, sendo os sistemas de classificação ensinados nos cursos de Biblioteconomia é possível que o desconhecimento se dê também por parte dos docentes.

O foco na Biblioteconomia tem como justificativa ser uma área que, tradicionalmente, desenvolve os sistemas de classificação como instrumentos para a organização, representação e recuperação de informações nos estoques de informação, competindo aos cursos de graduação a função de preparar e qualificar profissionais para ocupar seus espaços no mercado.

Essa problemática conduz ao objetivo de identificar os Cursos de Biblioteconomia, no Brasil, que ensinam a CIP, e em caso negativo, conhecer as razões. Isso nos leva a acreditar que o recebimento e o preenchimento do questionário sobre a temática despertam a atenção de professores para a lacuna.

\section{CLASSIFICAÇÕES BIBLIOGRÁFICAS}

As classificações bibliográficas têm origem na classificação dos conhecimentos 
humanos, cujo pioneiro foi Platão. Ele agrupou esses conhecimentos segundo as bases filosóficas. Depois, Aristóteles reuniu os conhecimentos em três grupos: Ética, compreendendo Economia, Política e Direito; Artes recreativas; e Teoria, em que se inserem a Matemática, a Física e a Teologia.

Mais tarde, Porfírio, em sua célebre Árvore, deu o primeiro exemplo de uma classificação binária, dividindo os conhecimentos em termos de grande extensão e pouca intensão, até chegar aos de pouca extensão e grande intensão. Isso quer dizer que é uma apresentação da técnica da classificação, partindo de assuntos gerais para específicos (BARBOSA, 1969).

O surgimento dos sistemas de classificação aparece com a necessidade de os bibliotecários sistematizarem os documentos, reunindo-os pelos assuntos, para melhor atender às necessidades dos usuários. No capítulo dedicado aos aspectos históricos da classificação da ciência - Vickery (1980) relata que as classificações desenvolvidas por bibliotecários em final do século XIX e no século $X X$ introduziram muitas subdivisões. Mas apesar de considerar um avanço nos sistemas de classificação, ainda assim eles se direcionavam à ciência.

Em princípio, a classificação foi descrita como um processo mental de designar e ordenar o universo do conhecimento, para determinar, com base em suas relações, o lugar preciso e exato das coisas que poderiam ser tanto idéias quanto documentos, num esquema organizado, com terminologia própria. Assim, para Robredo e Cunha (1994), a classificação, do ponto de vista simplista, consiste em colocar juntas coisas similares.

Essa também é a visão da CDU (1997), ao conceituar a classificação como um meio de estabelecer que grande número de conceitos, idéias, informações seja organizado em classes, ou seja, em grupos de coisas com algo comum. Também significa que os grupos têm distinções entre si, diferenciando uma classe de outras classes, pois se excluem as coisas que não têm a característica comum. Ao classificar (ao menos usando as classificações pré-coordenadas) determina-se ou elabora-se o termo ou expressão que represente $\mathrm{o}$ documento (notação), ao tempo em que se coloca o identificador de sua representação para que os assuntos semelhantes possam ser aproximados.

As classificações podem ser especializadas, como a CIP, quando se concentram ou estão voltadas para um assunto determinado, ou gerais, quando abrangem o universo da informação. Da mesma forma que a CDU, a CDD da qual aquela se origina, é uma classificação geral. Ambas são classificações 
documentárias e, como tal, destinam-se ao uso em unidades de informação, para a organização física de acervos, como guias para o conteúdo dos acervos, ou ao uso bibliográfico, para a descrição minuciosa do assunto dos documentos não limitados a um determinado acervo (CDU, 1997). Elas têm o objetivo final de facilitar a recuperação da informação representada, pelos usuários.

Devido à necessidade de ordenação do conhecimento, foram criados alguns sistemas de classificação, e outros, aperfeiçoados. Dentre eles, podemos destacar a CDD (Melvil Dewey), a CDU (Paul Otlet e Henri La Fontaine), a classificação de Bliss, a da Biblioteca do Congresso e a CIP. De acordo com Lima (2004), os sistemas são concebidos como conhecimento mapeado, os assuntos são diferenciados um a um, e os relacionamentos entre eles são representados especialmente. São úteis na organização de documentos impressos, sendo a principal delas a por assunto, mas outras variáveis também podem ser consideradas nesse processo, tais como: a data de publicação, a língua utilizada, a origem, a diferenciação para uso, o empréstimo ou consulta, os tipos de usuários, o tamanho dos volumes, o material utilizado e a função para que foi criado.

Quaisquer que sejam as variáveis consideradas na organização, os teóricos da classificação acreditam na ordem das coisas, ordem essa, relacionada à abstração das idéias, materializada em forma convencional, simbólica. Assim, um sistema de classificação tem o objetivo primordial de organizar o conhecimento de maneira que, quando o item de informação seja buscado pelo usuário, possa ser encontrado, ou recuperado como a área costuma denominar.

\subsection{CIP: Princípios Basilares}

A CIP é um sistema de uso internacional, que integra os sistemas de classificação documentária, permitindo rápida recuperação das informações por áreas tecnológicas, sendo, portanto, uma ferramenta de busca, que utiliza uma listagem de mais de 70 mil itens importantes, para acessar a informação contida em documentos de patentes, provendo uma recuperação precisa da tecnologia (INSTITUTO NACIONAL DA PROPRIEDADE INDUSTRIAL - INPI, 2007).

Para utilizar a CIP, é preciso entender seu mecanismo e distinguir dois enfoques principais. Por um desses enfoques, comumente designado de orientação industrial, técnica ou orientação, segundo o pedido de privilégio, as invenções são classificadas de acordo com os ramos da indústria, da técnica, ou da atividade humana em relação às quais são 
relevantes. A antiga Classificação de Patentes Alemã, que teve influência na CIP, utilizava esse enfoque (INPI, 2007).

Pelo outro enfoque, as invenções são classificadas de acordo com as funções para as quais são caracteristicamente pertinentes. Esse enfoque é comumente chamado de orientação, segundo a função, e servem como exemplo as classificações de patentes dos Estados Unidos da América e do Reino Unido (INPI, 2007).

Os dois enfoques dificilmente podem ser aplicados na sua pureza teórica. Algumas funções caracterizam certos ramos da indústria, sendo natural classificá-las nesses ramos. Por exemplo: fiação, tecelagem e malharia envolvem principalmente materiais têxteis e é natural considerá-los relevantes para a indústria têxtil, por isso figuram na CIP na Seção D Têxteis e papel (INPI, 2007). Por outro lado, transportar, embalar, estocar, suspender, levantar e rebocar são funções que dizem respeito a quase todos os ramos da indústria. As invenções relativas a essas funções se prestam para uma classificação orientada para a função. De fato, elas figuram na CIP na Seção B Operações de Processamento - Transporte (INPI, 2007).

O INPI (2007) considera que, embora a CIP seja, em princípio, orientada para a função, na realidade, ela combina os dois enfoques e resulta da experiência adquirida por pessoas, cujas tarefas diárias consistem na comparação entre invenções para as quais a proteção de patente é reivindicada e invenções similares já reveladas em documentos de patentes publicados.

A finalidade primordial da CIP é facilitar a recuperação da matéria técnica. Portanto, ela deve ser utilizada de maneira tal que uma mesma matéria técnica seja classificada e possa ser recuperada a partir de um mesmo local dentro da CIP. Esse local será mais relevante na busca dessa matéria (ORGANIZAÇÃO MUNDIAL DA PROPRIEDADE INTELECTUAL - OMPI, 2006).

Tendo em vista os dois tipos de enfoque, as informações encontradas em documentos de patentes são também informações inventivas e adicionais. As regras para escolha dos símbolos de classificação são as mesmas para os tipos de informação. Embora o Guia referencie, na maior parte das vezes, somente as invenções ou matérias técnicas de invenções, é preciso compreender que tais comentários aplicam-se, de igual maneira, a matérias técnicas cobertas por informações adicionais (OMPI, 2006).

\subsubsection{Informação Inventiva}

Essa é uma informação técnica revelada no documento de patente como um todo (por ex.: relatório descritivo, desenhos, reivindicações), que representa 
um acréscimo ao estado da técnica. A 2006).

informação inventiva é determinada no contexto do estado da técnica, utilizada como guia para as reivindicações do documento de patente, interpretadas com base no relatório descritivo e em desenhos.

Convém ressaltar que o acréscimo ao estado da técnica significa matéria nova, não obviamente revelada no documento de patente, nem representando parte do estado da técnica, mas sim, a diferença entre a matéria descrita no documento de patente e a coleção de todas as matérias técnicas pertencentes ao conhecimento público (OMPI, 2006). Por essa definição é que se afirma que, para desenvolver um produto ou um processo tecnológico, uma pesquisa deve iniciar, necessariamente, pela busca em bancos de patentes para não repetir o que já existe registrado (GARCIA, 2007).

\subsubsection{Informação Adicional}

Informação adicional é a informação técnica não trivial que, em si, não representa acréscimo ao estado da técnica, mas constitui informação útil para as buscas. A informação adicional complementa a informação inventiva ao identificar, por exemplo, os constituintes de uma composição ou mistura, os elementos de um processo, os componentes de uma estrutura ou, ainda, o uso ou aplicações de matérias técnicas classificadas (OMPI,

\subsection{Histórico da CIP}

A CIP teve sua primeira edição como resultante dos esforços da convenção européia para a Classificação Internacional de Patentes de Invenções, estabelecendose um tratado internacional em 1954. Porém, as discussões preliminares sobre ela datam de mais ou menos 1920 (SUSTER, 2005).

Logo após a assinatura de Estrasburgo, a Classificação Internacional de Patentes de Invenções, cuja primeira edição foi publicada em 1969, iniciou negociações para sua atualização. Um novo acordo discutido e celebrado em 1971 considerou a primeira edição da Classificação pelo Conselho da Europa e da OMPI, sendo denominado Acordo de Estrasburgo relativo à Classificação Internacional de Patentes. O referido acordo entrou em vigor em 1975, passando a ser administrado pela OMPI.

Portanto, o período de transição que começou em 1969 terminou em 1975, pondo fim à responsabilidade do Conselho da Europa no que diz respeito à CIP, tendo esta se tornado um sistema mundial, administrado por um organismo de âmbito internacional, vinculado à Organização das Nações Unidas (ONU). O acordo estabelece uma classificação comum para patentes de invenção, incluindo os pedidos 
de patentes publicados, certificados de inventores, modelos de utilidades $\mathrm{e}$ certificados de adição (todos designados documentos de patentes).

A CIP foi criada nos idiomas inglês e francês, sendo ambos os textos igualmente autênticos. Os textos oficiais da CIP podem ser publicados em outros idiomas, de acordo com o Artigo 3 (2) do Acordo de Estrasburgo supracitado, inclusive os da sétima edição estão publicados em português (OMPI, 2006). É revisada periodicamente, a partir de reuniões de peritos dos países-membros da OMPI, a fim de aperfeiçoar o sistema e considerar o desenvolvimento técnico, sendo disponibilizada em 10 volumes em papel, em CD-ROM e na web, no site do INPI $<$ http://www.inpi.gov.br> e no da OMPI $<$ http://www.wipo.int/classifications/fulltext/n ew_ipc/> (SUSTER, 2005).

\subsection{Objetivos da CIP}

A síntese seguinte tem como base a oitava edição, publicada pela OMPI, sob o $n^{\circ} 560 E 5 / 8$, em janeiro de 2006. Por ser um método de uso internacional e para se obter uma classificação uniforme de documentos de patentes, sua revisão objetiva: introduzir novas tecnologias através do aprimoramento das classificações existentes e a criação de novas classificações, eliminando os erros.
Todavia, a principal finalidade da CIP é ser uma ferramenta de busca eficaz para a recuperação de documentos de patentes pelos escritórios de propriedade intelectual e demais usuários, a fim de instituir a novidade e avaliar a etapa inventiva ou a não obviedade (avaliando, inclusive, o avanço técnico, os resultados úteis ou sua utilidade) das características técnicas dos pedidos de patentes.

Além disso, a Classificação tem outras finalidades, como, por exemplo: servir de a) instrumento para disposições organizadas dos documentos de patente, a fim de facilitar o acesso às informações tecnológicas e legais contidas nos mesmos; b) base de disseminação seletiva de informações a todos os usuários das informações de patentes; (c) base para investigar $\mathrm{o}$ estado da técnica em determinados campos da tecnologia; d) base para preparar estatísticas sobre propriedade industrial que permitam a avaliação do desenvolvimento tecnológico em áreas diversas (OMPI, 2006).

\section{ESTRATÉGIAS DA PESQUISA}

A pesquisa é um survey, utilizando-se o e-mail como instrumento de envio do questionário e recebimento das respostas. Pelo survey o questionário é enviado ao universo escolhido, e as respostas formam a amostra da pesquisa. Conforme Simsek 
(1999), o survey via e-mail é uma forma barata de realização de pesquisa e, com o desenvolvimento dos computadores, tornase uma das mais rápidas de se conseguir amostragem, e seu uso é relativamente recente.

Ademais, quando comparado às formas tradicionais, como a entrevista pessoal, e, o questionário via correios, o survey via e-mail mantém vantagens que justificam a escolha por essa técnica, tais como: altíssimas flexibilidades geográficas e de tempo; alta conveniência do preenchimento e manutenção do anonimato; facilidade de contato inicial com o respondente e retorno da resposta; economia de custos; velocidade na realização da pesquisa (SIMSEK, 1999).

As vantagens do survey não se restringem ao explicitado por Simsek (1999). Além delas, pudemos conhecer o Quality System da área de tratamento temático da informação no Brasil, que inclui os profissionais de referência. $\mathrm{Na}$ análise dos dados, eles permanecem sem identificação, a qual é substituída por uma numeração, estabelecida exatamente para não personalizar as falas nem identificálas.

\subsection{O Campo de Pesquisa: Universo e Amostra}

O campo de pesquisa foi delimitado em torno da comunidade universitária, mais especificamente, das Escolas
Brasileiras de Biblioteconomia e respectivos professores. A delimitação do campo da pesquisa obedeceu a duas etapas: na primeira, foram listadas 38 escolas de Biblioteconomia do país, por meio do site da Associação Brasileira de Educação em Ciência da Informação (ABECIN, 2007), objetivando identificar em cada uma delas os responsáveis pelas disciplinas do interesse da pesquisa. Foram remetidas 38 mensagens, solicitando os nomes e os e-mails dos professores que ministram as disciplinas Representação e / ou Indexação Précoordenada I e II, para posterior contato.

Depois de três reiterações, obtivemos 24 e-mails válidos. Dentre as respostas, três foram negativas, a saber: A Fundação Escola de Sociologia e Política de São Paulo - FESPSP - comunicou que não está autorizada a fornecer e-mails dos professores; A Universidade Federal do Paraná - UFPR - não oferece mais o Curso de Biblioteconomia; e a Universidade Federal de Santa Maria UFSM - não tem, no Curso de Arquivologia, as disciplinas indicadas. Algumas instituições (14), mesmo com as três solicitações, não responderam. Das 21 respostas que afirmativamente indicaram nomes dos professores, há escolas que enviaram dois nomes de responsáveis pelas disciplinas nomeadas anteriormente.

$\mathrm{Na}$ etapa seguinte, enviamos o questionário via e-mail ao seleto grupo de 
professores, indicados por suas estabelecemos uma categorização instituições. Entretanto, as respostas não constante dos conteúdos das perguntas.

foram tempestivas, havendo necessidade de reiterar o pedido mais duas vezes. Mesmo com as facilidades do uso do email, algumas respostas só foram conseguidas após as solicitações renovadas, atingindo 11 questionários válidos (respondidos), o que significa 44\% do total de 25 professores pesquisados. Mais uma vez, consideramos esse um resultado relevante, pois o percentual é representativo para uma amostragem por survey.

\subsection{Instrumentos de Coleta de Dados}

Utilizamos a pesquisa bibliográfica em fontes convencionais e eletrônicas constantes de estudos publicados em livros, guias, teses e artigos referentes aos assuntos abordados para delimitar 0 problema, justificar a pesquisa, revisar a literatura e analisar os dados. Na segunda etapa, elaboramos um questionário, encaminhado via e-mail, ao Quality System da área, no Brasil, obtendo retorno de 11 questionários respondidos.

\subsection{Análise e Interpretação dos Dados}

Encerrado o período estabelecido para a coleta dos dados, iniciamos sua organização utilizando percentuais simples. $\mathrm{Na}$ interpretação das questões,

\subsubsection{Perfil do Quality System}

Procedemos à análise das respostas, alertando que os percentuais são calculados com base nos 11 questionários respondidos. O tempo de trabalho em Instituições de Ensino Superior varia entre cinco e 29 anos, sendo que, ministrando disciplinas na temática indicada, houve uma variação de tempo entre cinco e 25 anos. Comprova-se, então, que esses professores são profissionais com experiência, expressa pelo tempo de ensino na disciplina. Ademais, todos têm, no mínimo, curso em nível de Mestrado, destacando-se quatro doutores e um doutorando, ou seja, trata-se de um grupo que integra os Cursos de Biblioteconomia do País, com suficiente e expressiva qualificação.

\subsubsection{Classificações Enciclopédicas Versus Específicas}

Há uma concordância em se considerar que a utilização das classificações universais (CDD e CDU) não se aplica às especificidades da tecnologia, reforçando a utilização de ajustes ou de combinações com outros sistemas. Essa afirmativa está demonstrada pelas falas de dois professores: "Tudo é possível, e quando necessário, faz-se os devidos ajustes a cada realidade" ( $\mathrm{P}$ 7); "Não 
completamente. Acredito que, de acordo com o nível de especificidades que a área tecnológica está alcançando, é preciso algumas adaptações" ( $P$ 9). Outro professor se expressa de forma mais contundente: "As classificações enciclopédicas podem tratar a informação tecnológica de maneira genérica. Para uma classificação mais específica, é necessário, claro, utilizar classificações criadas para essa finalidade especifica" ( $P$ 1). Esse se refere à necessidade de o documento ser representado sob o conteúdo mais específico, que $\mathrm{O}$ abranja com total exaustividade, isto é, o sistema de classificação deve permitir a representação do maior número de conceitos possíveis.

\subsubsection{Conhecimento da CIP}

Mesmo com a experiência expressa pelo tempo de ensino na disciplina, menos da metade $(45,5 \%)$ dos professores pesquisados admitiu conhecer a CIP, e parte deles, como eles mesmos indicam, superficialmente. Entretanto, todos foram unânimes em afirmar que gostariam de aprofundar seus conhecimentos - os que conhecem a CIP - e procurar conhecer os que ainda não vivenciaram essa oportunidade.

Mesmo com esse índice de respostas, os professores afirmam que conhecem o sistema de classificação dos documentos de patente de forma superficial: "Tenho conhecimento, mas não considero que tenho domínio suficiente" (P 4); "Não sou experto no assunto, mas conheço um pouco" ( $\mathrm{P}$ 2); "Sim, já vi casos de tratamento de patentes" ( $(\mathrm{P} \quad 5)$. São pessoas que reconhecem suas limitações, mas ainda não atentaram para adquirir o domínio suficiente ou se tornar expert no assunto. $\mathrm{Ou}$, demonstram pouco conhecimento sobre como os documentos tecnológicos, representados pelas patentes, são classificados e, portanto, consideram-nos pela vertente dos instrumentos tradicionalmente utilizados para a indexação pós-coordenada, conforme a citação a seguir: "Imagino que através de tesauros ou vocabulários controlados da área" (P 6).

Assim, espera-se que, depois de participar desta pesquisa, esses informantes se considerem alertados para ampliar seus conhecimentos sobre a CIP.

\subsubsection{Interesse em Conhecer a CIP}

Os que responderam positivamente sobre $\mathrm{O}$ interesse em conhecer a CIP somam $45,5 \%$ dos pesquisados. Tal como referimos anteriormente sobre o uso das classificações enciclopédicas, alguns demonstram interesse: "Sim, conheço. Gostaria de conhecê-la melhor, embora o seu uso seja fácil” (P 8). Paradoxalmente, há professores que ainda não foram despertados para o ensino da CIP: "Sei da 
sua existência, mas nunca trabalhei com ela" (P 7); "Tenho conhecimento superficial" (P 4).

Embora reconheçamos que, ao ser alertado, pode-se supor que esse contexto mude, destacamos o fato de, ainda assim, no geral, os informantes não revelarem iniciativas para solucionar essa defasagem. Corrobora essa idéia a declaração do $P$ 1: "O tema é muito interessante. Chama a atenção para a necessidade de abordar a CIP. Creio que servirá de alerta para a inclusão do tema em disciplinas que tratam da Informação Científica e Tecnológica”. No entanto, há alguns professores que relacionam o ensino a sua prática profissional. Não há dúvidas de que a metodologia é interessante, mas não deve ser confundida ou usada como motivo para não inovar a disciplina. Ao contrário, por ser um conhecimento especializado e por admitir a necessidade de ampliação do conhecimento é que ações devem ser promovidas para comprovar o real interesse: "Um conhecimento novo é uma forma de evolução intelectual, portanto, gostaria sim. Só que se trata de um conhecimento muito especializado. Como profissional da informação, caso trabalhasse nessa área, seria indispensável conhecê-la profundamente, pois seria um instrumento de trabalho" ( $P$ 3).

Convém, ainda, registrar que 36,4\% dos que não conhecem a CIP dizem ter interesse em fazê-lo, agregando-se aos que já a conhecem, declarando-se, pois, interessados em aprofundar seus conhecimentos, por ser esse um assunto importante na preparação de profissionais da área da Biblioteconomia. Reputamos tais respostas como condizentes com a função de professor, a quem cabe não somente ensinar aquilo que ele usa ou em que tem interesse especial. O sentido da educação é estimular o aluno para que amplie seus horizontes, suas perspectivas criadoras e criativas, uma permanente relação entre informação e conhecimento, o que, certamente, será revertido em ampliação do conhecimento também para o professor, sobretudo em uma sociedade de aprendizado constante, em que aluno e professor devem se colocar como aprendentes.

Exceção para tomada de iniciativa restringe-se ao $P$, que assim se posiciona: "Tenho sim interesse, por acreditar que ela possa contribuir para o ensino das disciplinas que ministro. Estou revendo os conteúdos programáticos das disciplinas que ministro e pretendo incluí-la no ensino de outros sistemas de classificação por acreditar na sua importância”.

\subsubsection{Ensino da CIP nos Cursos de Biblioteconomia}

Numa das questões dirigidas aos pesquisados, indagamos o seguinte: Se 
você conhece a CIP, ensina-a em sua disciplina? $81,82 \%$ dos pesquisados responderam que não, embora um dos professores a ensine em outra disciplina: "Em outra disciplina de Fonte de Informação, que antecede a indexação, quando explico sobre patentes, falo da Classificação Internacional de Patentes" (P $5)$.

Percebemos pelas respostas aos questionários que os conhecedores da CIP e sabem que seu uso é fácil juntam-se à maioria dos que afirmam não ensiná-la. Se o objetivo da disciplina é ensinar / aprender como utilizar os sistemas de classificação, entendemos que a idéia é experienciar a utilização da diversidade de instrumentos de classificação quando não se pode trabalhar a "geração de instrumentos para sua recuperação".

(DANUELLO; GUIMARÃES, 2005, p. 157).

No caso da CIP, com duas possibilidades: uma tabela básica e uma tabela avançada, possibilitando exercitar os princípios teóricos de exaustividade e especificidade. Por outro lado, a representação no nível da técnica se enquadra em tal atividade industrial, ou ainda tal patente é utilizada para esta ou aquela função para a qual a tecnologia foi criada. Seria, por exemplo, o caso das embalagens que, tanto indicam o produto com o qual ela é fabricada quanto a função para a qual foi criada. Convenhamos que essa é uma experiência ímpar para alunos e professores.

Entretanto há quem se posicione da forma a seguir: "Não. O objetivo da minha disciplina é levar o aluno a conhecer as classes que organizam a informação, nas bibliotecas, além de aprender como utilizar as tabelas, já que são nossos instrumentos de trabalho. O aluno sai com um entendimento que nas tabelas estudadas encontram-se arrolados e representados por um número todo o conhecimento humano. Além de conscientizá-los de que só nós sabemos como organizar a informação e recuperá-la. Hoje, percebe-se que não dão muito valor à classificação. Fica a pergunta: como se recuperaria a informação nos dias atuais?" (P 3).

Essa declaração deixa claro que há, nas Instituições de Ensino, professores que ministram suas disciplinas com ementas elaboradas no Século passado, as quais, muitas vezes, mantêm o status quo sem admitir atualizações de conteúdos. Isso nos conduz a refletir sobre a emergente necessidade de se repensar 0 desenvolvimento das tecnologias de informação e comunicação, buscando outras formas de representar a informação, outros conteúdos, como, por exemplo, a possibilidade de utilização de um sistema de classificação via web. Em língua ao alcance do usuário, e da maneira que se pretender utilizar, isto é, pela classificação básica ou pela avançada para classificar a 
tecnologia, inclusive, pelo ramo industrial ou pela função para a qual o produto foi criado.

\subsubsection{Indicação da CIP na Disciplina}

Outra pergunta dirigida aos informantes foi se o professor que conhece a CIP $(45,5 \%)$ comenta sobre ela em sala de aula, ao que $27,3 \%$ responderam que sim: "Sim. Eu comento com meus alunos que existem outros sistemas de classificação e cito a Classificação Internacional de Patentes" (P 8); "Sim. Ela é de fundamental importância para classificar com precisão os inventos tecnológicos" (P 7).

Essas são posturas que demonstram que, mesmo conhecendo a utilidade e a importância da CIP, alguns professores ainda não transmitem esse conhecimento, talvez porque as grades curriculares das várias Instituições aqui pesquisadas ainda não tenham colocado a CIP nas ementas de suas respectivas disciplinas. Mas isso seria reduzir o conteúdo do ensino sem atentar para as atualizações necessárias e demandadas pelo ambiente em que ora se vive.

\subsubsection{Instituições que Ensinam o Uso da CIP}

Embora o INPI ofereça cursos periodicamente sobre como usar a CIP sistema de classificação eficiente, que permite rápida recuperação dos documentos da área tecnológica - 72,7\% dos professores pesquisados responderam que não têm conhecimento de qualquer instituição que prepare pessoas para o uso e a prática desse sistema.

O INPI situa-se no Rio de Janeiro e, talvez, devido a problemas ligados à sua situação estrutural e financeira, não despertou para convidar professores dos Cursos de Biblioteconomia para uma turma especial sobre a CIP. Essa é uma idéia que deve ser posta em prática, porquanto existem professores que, mesmo conhecendo superficialmente a CIP, desconhecem as atividades daquele instituto. Em março de 2006, o INPI, em parceria com o Instituto de Tecnologia do Paraná, realizou um curso sobre a CIP para técnicos daquela empresa. Acreditamos que exista a possibilidade de isso se repetir em algum evento da Biblioteconomia em que sejam oferecidos cursos. Nesses eventos, há concentração de profissionais e professores em determinada localidade, ficando as despesas exclusivamente para deslocamento e hospedagem do técnico do INPI, designado para ministrar o curso. Por outro lado, pode-se estimular a existência de demanda, com a indicação de cursos a distância, hoje facilitados pela web.

Esse resultado chama a atenção, também, para se ressaltar, nas escolas e nos Cursos de Biblioteconomia, a necessidade de ampliar e atualizar os 
conhecimentos acerca dos sistemas de classificação dos profissionais que ministram disciplinas da área: tratamento temático da informação e incluir a CIP em disciplinas que tratam da informação tecnológica, adotando o exemplo do professor que a usa em sua disciplina de Fontes de Informação.

\section{CONSIDERAÇÕES FINAIS}

A explicitação dos elementos básicos da CIP, além de referencial teórico para a presente pesquisa, tem objetivo de demonstrar a possibilidade do ensino de um sistema encontrado na língua vernácula, disponibilizado em meio eletrônico, constantemente atualizado para acompanhar o desenvolvimento da tecnologia. Para as instituições de ensino públicas, sempre com problemas financeiros, dispor de um instrumento, a custo zero, é um privilégio, devido às possibilidades e facilidades que isso representa.

A CIP é ainda um sistema de classificação hierárquico, que torna possível a organização da informação tecnológica, seja pelo tipo de técnica utilizada, seja pela função do produto tecnológico. As atualizações constantes a tornam um sistema completo e especializado para a área, por recuperar informações contidas nos documentos de patentes.
Os resultados da pesquisa mostraram que existe um conhecimento demonstrado pelo Quality System da pesquisa no que se refere à área da utilização dos sistemas de classificação, da representação das informações, confirmando-se a suposição de que, nos Cursos de Biblioteconomia, a CIP não é ministrada por meio dos seguintes percentuais: menos da metade dos pesquisados $(45,5 \%)$ conhece a CIP; $81,8 \%$ não ensinam ou não se referem a ela em suas disciplinas; $72,7 \%$ desconhecem que instituições, no Brasil, usam a CIP. De outra parte, há somente uma iniciativa digna de nota, descrita no item 3.3.5. Os percentuais acima citados indicam impedimento para que a CIP possa ser utilizada para descrever tais documentos, permanecendo a interrogação: Se o documento de patente detém informações tecnológicas, fontes de desenvolvimento, não disponibilizadas em outro tipo de documento, por que não incluir a CIP nas disciplinas curriculares?

Pode-se justificar que os dados acima referidos tenham relação com a posição que o Brasil ocupa no cenário mundial, no que respeita aos depósitos de patentes, e ao pouco investimento que as empresas fazem em pesquisa e desenvolvimento. Sobre essa situação, Macedo e Barbosa (2000) reafirmam que o sistema de patentes, especialmente como fonte de informação técnico-produtiva, é ainda pouco conhecido em território nacional. 
Exemplificam o desconhecimento afirmando que $\mathrm{o}$ pesquisador brasileiro torna o caminho de busca tortuoso, por se dirigir a uma biblioteca quando necessita de uma informação técnico-produtiva, ao invés de consultar um banco de patentes. Em geral, os sistemas de classificação estão baseados no conhecimento científico de forma que a informação tecnológica representada por tais sistemas, fica camuflada por sua inadequação.

Com base na importância da informação tecnológica, os resultados indicados no item 3.3.2 realçam as dificuldades enfrentadas pelos profissionais da informação, ao classificar ou representar com especificidade assuntos diversos, especialmente os resultantes de tecnologia, usando sistemas de classificação enciclopédicos, que impossibilitam o atendimento das funções para as quais a patente é inventada.

Há que mencionar as expectativas positivas: os professores que mencionam a CIP em suas disciplinas; 0 interesse em ampliar os conhecimentos sobre ela; e a afirmativa de que a pesquisa possa ter despertado a atenção para o ensino de mais um sistema de classificação nas disciplinas indicadas ou em outras com que tenham correlação. Essas razões conduzem a afirmar que os objetivos do trabalho foram atingidos, possibilitando o posicionamento dos docentes para um assunto importante, como é a tecnologia, os documentos de patente e, por via de conseqüência, a CIP, para a representação, disseminação e recuperação da informação tecnológica.

Certamente o tema não se esgota com essa pesquisa, até porque, na era das inovações constantes, as mudanças acontecem a passos largos. Entretanto é necessário que alunos, professores, pesquisadores e profissionais reflitam com seriedade sobre elas, sobre os tempos que se caracterizam por mudanças constantes que utilizam e originam novas informações. Sem dúvida alguma, a informação tecnológica é chave fundamental para o desenvolvimento e está a merecer um tratamento especial a respeito de sua organização, estoque e utilização. A responsabilidade desses profissionais é impedir a auto-exclusão profissional por falta de eficiência e atualização, tanto no que se refere ao conhecimento, em si, quanto ao acompanhamento das inovações tecnológicas ou, mais que isso, permitir a exclusão do Brasil dentre os países desenvolvidos.

Cabe, pois, às escolas de Biblioteconomia encontrar soluções que aumentem a eficiência dos seus currículos incluindo, especialmente, entre os sistemas de classificação, a CIP, para investir no aprimoramento de seus profissionais, tornando o profissional da informação competente, eficiente e adequado às 
condições de mercado exigidas pela INSTITUTO NACIONAL DA

sociedade do Século XXI.

Compete aos autores do estudo sensibilizar pessoas para evitar que esses questionamentos se guardem nas prateleiras de suas memórias e possam, num breve espaço de tempo, integrar a CIP às disciplinas dos Cursos de Biblioteconomia brasileiros.

\section{REFERÊNCIAS}

ASSOCIAÇÃO BRASILEIRA DE EDUCAÇÃO EM CIÊNCIA DA INFORMAÇÃO - ABECIN. Escolas brasileiras de biblioteconomia. Disponível em:

<http://www.abecin.org.br/portal/abecin>. Acesso em: 11 abr. 2007.

BARBOSA, A. P. Teoria e prática dos sistemas de classificação bibliográfica. Rio de Janeiro: Instituto Brasileiro de Bibliografia e Documentação, 1969.

CLASSIFICAÇÃO DECIMAL UNIVERSAL CDU. Tradução de Francisco F.L. de Albuquerque e Maria Thereza G.F. de Albuquerque. Revisão de Agenor Briquet de Lemos. Brasília, IBICT, 1997.

DANUELLO, J. C.; GuimARÃES, J. A. C. Produção científica docente em tratamento temático da informação nos cursos de biblioteconomia do Mercosul: uma análise preliminar. Transinformação, Campinas, v.17, n.2, p.153-168, maio/ago. 2005.

GARCIA, J. C. R. Usar ou não usar a patente: eis a questão! In: KAIMEN, M. J. G.; CARELLI, A. E. Recursos informacionais para compartilhamento da informação: redesenhando acesso, disponibilidade e uso. Rio de Janeiro: Epapers, 2007. p. 49-73.
PROPRIEDADE INDUSTRIAL - INPI. Banco de patentes do INPI. Rio de Janeiro. Disponível em:<http://www5.inpi.gov.br/clientes/inpi/po rtal_INPI>. Acesso em: 24 mar.2007.

KAPSNER, O. L. The Catholic University of America Library in action. Special Libraries, New York, v. 47, n.7, p. 307-313, Sept. 1956.

LIMA, V. M. A. Da classificação do conhecimento científico aos sistemas de recuperação de informação: enunciação de codificação e enunciação de decodificação da informação documentária. 2004. 156 f. Tese de Doutorado - Universidade de São Paulo, São Paulo, 2004. Disponível em: <http://www.teses.usp.br/teses/disponiveis/ 27/27143/tde-06032006-

150120/publico/Daclassificacaodoconheci mentocientificoaossistemasderecuperacao deinformacao.pdf'>. Acesso em: 9 mar. 2007.

MACEDO, M. F. G.; BARBOSA, A. L. F. Patentes, pesquisa e desenvolvimento: um manual de propriedade intelectual. Rio de Janeiro: FIOCRUZ, 2000.

ORGANIZAÇÃO MUNDIAL DA PROPRIEDADE INTELECTUAL - OMPI. Classificação Internacional de Patentes: guia. 8. ed. Rio de Janeiro, 2006. Disponível em: em:<http://www.portallusofonia.org/content/view/79/51/>. Acesso em: 24 mar.2007.

ROBREDO, J.; CUNHA, M. B. Documentação de hoje e de amanhã: uma abordagem informatizada da biblioteconomia e dos sistemas de informação. São Paulo: Global, 1994.

SIMSEK, Z. Sample surveys via eletronic mail: a compreensive perspective. Revista de Administração de Empresas, São Paulo, v. 39, n. 1, p. 77-83, jan./mar. 1999.

SUSTER, R. Classificação Internacional de Patentes. Curitiba: 2005. Disponível em: 
<http://www.prppg.ufpr.br/documentos/pes quisas/npi>. Acesso em 24 mar. 2007.

VEIGA, E. A.; MARTHA, M. O. B. Classificações de obras literárias. Porto Alegre: Sagra, 1986.

VICKERY, B. C. Classificação e indexação nas ciências. Rio de Janeiro:

BNG/Brasilart, 1980.

\section{Title}

The International Patent Classification (IPC) teaching in brazilian's library science undergraduate courses.

\begin{abstract}
The identification of the undergraduate courses in Library and Information Science where the International Patent Classification (IPC) is taught, aims to arise the interest for this subject among librarians. The sample of the study was composed by undergraduate courses which were identified on the ABECIN's website. The research was based on the survey technique and the data collection was carried out by open-ended questions questionnaire which was sent and answered by e-mail. Even though the patent document contains relevant information to promote technological development of nations, the study concluded that the majority of the analyzed institutions do not incorporated this content in Classification subjects.
\end{abstract}

\section{Keywords}

Technological Information. Patents. International Patent Classification. Patent Classification.

\section{Título}

La enseñanza de la Clasificación Internacional de Patentes nos cursos de bibliotecologia do Brasil.

\section{Resumen}

Para determinar en quales cursos de Bibliotecologia se enseña la Clasificación Internacional de Patentes (CIP), se intenta despertar en los profesionales del área la necesidad de conocer o profundizar eses conocimientos. Los cursos, objeto deste estudio, fueron identificados por el sitio de Asociación Brasileña de la Educación en Ciencias de la información (ABECIN). La técnica utilizada es la survey, siendo el correo electrónico la forma de enviar el cuestionario y recibir las respuestas. El cuestionario fue formulado con preguntas abiertas. Aunque el documento de la patente contiene información pertinente para la promoción del desarrollo tecnológico de naciones, no recibe un tratamiento compatible con las instituciones de la educación do Brasil, o, en la mayoría de los cursos que se estudian formas de clasificar el conocimiento, la CIP no es citado en las disciplinas.

\section{Palabras Clave}

Clasificación Internacional de Patentes. Enseñanza de Clasificación Internacional de Patentes. Clasificación de Patentes.

Recebido em: 29.04.2008

Aceito em: 10.02.2009 